\title{
Analysis of Saturated Synchronous Machine considering d-q Axis Coupling Reactance
}

\author{
B Singh, and A. K. Chandel, Member, IEEE, Arvind Kumar
}

\begin{abstract}
The present paper describes a study of small signal performance of synchronous machines connected to a large power system network through transmission line under steadystate operation by considering influence of saturation with cross-magnetizing phenomenon between $\mathrm{d}$ - and q-axis circuits. In the method, mutual reactance $X_{d q}$ due to the cross magnetizing phenomenon can be consider on the basis of $d$ - $q$ axis magnetic field analysis. The quantitative accuracy requires the magnetic coupling between $d$ - and q-axis circuits be considered. Subsequently, steady-state reactances are analyzed by considering mutual reactances $X_{d q}$ due to cross magnetizing

phenomenon. Synchronous machines have a nonlinear characteristic due to saturations and cross-magnetization phenomena, so that $d-q$ axes inductances vary depending on the current amplitude and the load angle. Therefore, usually the un-coupled $d-q$ model with constant parameters might not be suitable to represent accurately the performance of the electrical machine.
\end{abstract}

Index Terms - Synchronous Machines, Turbine Generators, Saturated Synchronous Machines, Saturated Synchronous, Reactances, Cross-Magnetizing Phenomenon.

$\begin{array}{ll}A, B & \text { State equation matrices. } \\ \lambda_{d}, \lambda_{q} & d q \text {-axis flux linkage [V.s] } \\ \lambda_{a d}, \lambda_{a q} & d q \text {-axis magnetizing flux linkage [V.s] } \\ L_{l} & \text { Leakage inductance [H]. } \\ i_{d}, i_{q} & d q \text {-axis current [A]. } \\ i_{f d} & \text { d-axis field current [A] } \\ \lambda_{f d} & \text { Field flux linkage in d-axis [V.s ] } \\ L_{d f} & \text { Field flux inductance in d-axis [H]. }\end{array}$

B.Singh is student of M.Tech (under the guidance of A. K. Chandel) from Electrical Engineering Department, National Institute of Technology Hamirpur HP 177001 India (e-mail: bharat7091988@gmail.com).

A.K.Chandel is with the Head of Electrical Engineering Department, National Institute of Technology Hamirpur HP 177001 India (e-mail: ashchandeli@gmail.com).

\begin{tabular}{|c|c|}
\hline$L_{a d}^{\prime \prime}, L_{a q}^{\prime \prime}$ & Equivalent magnetizing inductance of $d q$-axis $[\mathrm{H}]$. \\
\hline$L_{1 d}, L_{1 q}$ & Inductance of $d q$ axis damper bar $1[\mathrm{H}]$. \\
\hline$L_{2 q}$ & Inductance of q-axis damper bar $2[\mathrm{H}]$. \\
\hline$L_{d q}$ & $d q$-axis coupling inductance $[\mathrm{H}]$ \\
\hline$p$ & Power developed by machine [MW] \\
\hline$\Delta \omega$ & Speed deviation in pu. \\
\hline$\Delta \delta$ & Rotor angle deviation in pu elec. rad. \\
\hline$\Delta \lambda_{f d}$ & Change in d-axis field flux linkage in pu \\
\hline$\Delta \lambda_{1 d}$ & $\begin{array}{l}\text { Change in d-axis damper bar 1field flux linkage in } \\
\text { pu. }\end{array}$ \\
\hline$q, \Delta \lambda_{2}$ & $\begin{array}{l}\text { Change in q-axis damper bar } 1 \& 2 \text { field flux linkage } \\
\text { in pu. }\end{array}$ \\
\hline$\Delta T_{m}$ & Change in input torque to the turbine shaft in pu. \\
\hline$\Delta E_{f d}$ & $\begin{array}{l}\text { Change in field flushing voltage to the generator in } \\
\mathrm{pu} \text {. }\end{array}$ \\
\hline$K_{D}$ & $\begin{array}{l}\text { Damping torque coefficient in pu torque /pu torque } \\
\text { deviation. }\end{array}$ \\
\hline$K_{S}$ & Synchronizing torque coefficient in pu torque/rad. \\
\hline$\omega_{0}$ & Rated speed in elec. rad/s. \\
\hline
\end{tabular}

\section{INTRODUCTION}

$\mathrm{A}_{\mathrm{ta}}^{\mathrm{c}}$ CCURATE determination of circuit constants is necessary predict steady-state and transient characteristics of synchronous generators. Generally, as a method to describe characteristics of synchronous generators, the reactances defined on the $d q$ coordinate system have been used. But as power density of synchronous machines is steadily increased, the variation of synchronous reactances by magnetic saturation becomes large. Therefore, accurate determination of saturated $\mathrm{d}$ - and q-axis synchronous reactances has been studied extensively.

Due to the nonlinearity introduced by the saturation permeability pattern around $\mathrm{d}$-axis is nonsymmetrical so results dissymmetric in flux linkages, $d$-axis flux produced q-axis flux linkages and vise-versa. This effect is secondary in nature so 
many of the researchers do not conceder.

The synchronous machine with damper bar under saturation condition, consider the cross magnetizing effect and various factor associated with machine on system stability. In addition to the state space representation and model analysis, block diagram representation and torque angle relationship to analyze the system stability. [6].

There are many reports about the saturation of reactance, and many calculating methods have been presented. Use of unsaturated and saturated reactances is widely applied to current electric design and power system simulation, though the distinction between unsaturated and saturated values is a classical expression of reactance variation affected by magnetic saturation [1]. Although the state space model is provided with an equivalent circuit and magnetic saturation [4], the cross-coupling phenomenon is not considered. Reactance calculation methods have been proposed using numerical magnetic field analysis which considers changes of such reactances more precisely [2]-[6]. Those methods are based on a conventional expression of $\mathrm{d}$ - and q-axis equations that do not consider magnetic coupling between $\mathrm{d}$ - and q-axis circuits. However, this magnetic coupling has been shown experimentally, and a calculation of synchronous reactances that considered the coupling has also been presented [7] [8]. It was pointed out that coupling between $\mathrm{d}$ - and q-axis circuits cannot be ignored when magnetic saturation becomes large.

The magnetizing path saturation is represented - either a nonlinear element or by adjusting the magnetic branch inductance [10]. In this paper, the cross-coupling due to the saturation does not consider.

In this paper, the steady state analysis of synchronous machine considering the cross-magnetization effect under saturation and some calculation examples are shown. Furthermore, synchronous reactances calculated according to a conventional definition are compared with the equivalent synchronous reactances that considered the mutual reactance between $\mathrm{d}$ - and q-axis circuits for various load conditions. It is seen that equivalent synchronous reactances are smaller than conventional synchronous reactances with higher load because mutual reactance between $\mathrm{d}$ - and q-axis circuits becomes large. [1], the conventional equation for the machine voltage and flux linkages in $d q$ - axis is modified, the equivalent equation is given.

\section{Steady-St ATE REACT ANCE ANALYSIS}

\section{A. dq Axis Equations Considering Magnetic Saturation}

The proposed method calculates field current deviation and introduced steady state reactance under a load by using the $\mathrm{d}$ $q$ axis equations of a synchronous machine. In this section, the $\mathrm{d}-\mathrm{q}$ axis equations are shown. Equations leading to them are shown as per unit system.
Generally, time variations of reactance, looked at with an armature coordinate system, depend on both saliency and magnetic saturation. Considering only saliency, values of self and mutual reactance are largest on the $\mathrm{d}$-axis, and are smallest on the q-axis. At the presence of the saturation considering cross- magnetization phenomenon the equation given in [1], based on [3], is get modified as

$$
\begin{aligned}
& \lambda_{\text {adequ }}=-\left[L_{a d}+\frac{L_{d q}}{\left(i_{d}-i_{f}\right)} i_{q}\right]\left(i_{d}-i_{f}\right)+\mathrm{L}_{a d} i_{1 d} \\
& \lambda_{\text {adequ }}=-\left[L_{a d}\left(i_{d}-i_{f}\right)+L_{d q} i_{q}\right]+\mathrm{L}_{a d} i_{1 d}
\end{aligned}
$$

Here the value of the $i_{f}$ field current, $i_{1 d}$ d-axis damper winding current is [3].

Thus equation yields;

$$
\begin{gathered}
\lambda_{\text {aqequ }}=L_{a q}^{\prime \prime}\left(-i_{q}+\frac{\lambda_{1 q}}{L_{1 q}}+\frac{\lambda_{2 q}}{L_{2 q}}\right)-L_{d q} \frac{L_{a q}^{\prime \prime}}{L_{a q}} i_{d} \\
\lambda_{\text {aqequ }}=\lambda_{a q}-L_{q d}^{\prime \prime} i_{d} \\
\lambda_{\text {qequ }}=\lambda_{\text {aqequ }}-L_{l s} i_{q}=\lambda_{a q}-L_{q d}^{\prime \prime} i_{d}-L_{l s} i_{q}
\end{gathered}
$$

Where $\lambda_{a d}$ and $\lambda_{a q}$ are the magnetizing flux linkages in $\mathrm{d}-$ axis and q-axis respectively.

$$
\begin{gathered}
\lambda_{d}=-L_{l} i_{d}+\lambda_{a d} ; \lambda_{q}=-L_{l} i_{q}+\lambda_{a q} \\
\lambda_{a d}=L_{a d}^{\prime \prime}\left(-i_{d}+\frac{\lambda_{f d}}{L_{f d}}+\frac{\lambda_{1 d}}{L_{1 d}}\right) ; \lambda_{a q}=L_{a q}^{\prime \prime}\left(-i_{q}+\frac{\lambda_{1 q}}{L_{1 q}}+\frac{\lambda_{2 q}}{L_{2 q}}\right) \\
L_{a d}^{\prime \prime}=\frac{1}{\frac{1}{L_{a d}}+\frac{1}{L_{f d}}+\frac{1}{L_{1 d}}} ; L_{a q}^{\prime \prime}=\frac{1}{\frac{1}{L_{a q}}+\frac{1}{L_{1 q}}+\frac{1}{L_{2 q}}} \\
L_{d q}^{\prime \prime}=L_{d q} \frac{L_{a d}^{\prime \prime}}{L_{a d}} ; L_{q d}^{\prime \prime}=L_{d q} \frac{L_{a q}^{\prime \prime}}{L_{a q}}
\end{gathered}
$$

Here, $\lambda_{\text {adequ }}, \lambda_{\text {aqequ }}$ is the equivalent magnetizing flux linkages, $\lambda_{\text {dequ }}, \lambda_{\text {qequ }}$ are the total equivalent flux linkage in $\mathrm{d}-$ and qaxis respectively. And $L_{d q}$ is the cross coupling inductance due to the saturation [1]. In the above equation $L_{f q}$ is [1] and $L_{a q}$ is the inductance of the q axis magnetizing branch [3]. 
Where $i_{d}$ and $i_{q}$ are the d-axis and q- axis armature currents, and $i_{f}$ is the field current. $\lambda_{d}, \lambda_{q}$ and $\lambda_{f}$ are the flux linkage in $\mathrm{d}$-axis, $\mathrm{q}$ - axis and field windings respectively.

According to synchronous machine model of IEEE Standard model of type 3.3 the equations are:-

d- Axis voltage expressed as:-

$$
V_{d}=-R_{a} \cdot i_{d}-\omega \cdot L_{q} \cdot i_{q}+\frac{d \lambda_{d}}{d t}
$$

q- Axis voltage expressed as

$$
V_{q}=-R_{a} \cdot i_{q}+\omega \cdot L_{d} \cdot i_{d}+\frac{d \lambda_{q}}{d t}
$$

On the other hand, the un-symmetry in permeability distribution of a synchronous machine, which is influenced by magnetic flux distribution. Considering permeability distribution of stator and rotor cores by magnetic saturation at on-load operation, values of self and mutual reactances are not largest on d-axis, and are not smallest on q-axis. Accordingly, expressions of flux linkages that consider magnetic saturation can be get modified and expressed as follows

$$
\begin{aligned}
& V_{d s}=-R_{s} \cdot i_{d s}-\omega \lambda_{q e q u}+\frac{d \lambda_{d}}{d t} \\
& V_{q s}=-R_{s} \cdot i_{q s}+\omega \lambda_{\text {dequ }}+\frac{d \lambda_{q}}{d t}
\end{aligned}
$$

Substituting the equation (3) - (2) in (6) yield

$$
\begin{gathered}
V_{d s}=-R_{s} \cdot i_{d s}-\omega \lambda_{q e u}+\omega L_{q d}^{\prime \prime} i_{d}+\frac{d \lambda_{d}}{d t} \\
V_{q s}=-R_{s} \cdot i_{q s}+\omega \lambda_{d e u}-\omega L_{d q}^{\prime \prime} i_{q}+\frac{d \lambda_{q}}{d t}
\end{gathered}
$$

Where $L_{q d}^{\prime \prime}$ and $L_{d q}^{\prime \prime}$ is equivalent mutual inductance between $\mathrm{d}$ and $\mathrm{q}$ axis circuit and it is introduce when saturation take place, the value of, $i_{d}, i_{q}$ and $i_{f}$ which change with saturation condition. Further solving the above equation (7)(8)

$$
\begin{aligned}
& V_{d s}=-R_{s} \cdot i_{d s}+\omega L_{q}^{\prime \prime} i_{q}-\omega\left(L_{a q}^{\prime \prime}\left(\frac{\lambda_{1 q}}{L_{1 q}}+\frac{\lambda_{2 q}}{L_{2 q}}\right)\right)+\omega L_{q d}^{\prime \prime} i_{d} \\
& V_{q s}=-R_{s} \cdot i_{q s}-\omega L_{d}^{\prime \prime} i_{d}+\omega\left(L_{a d}^{\prime \prime}\left(\frac{\lambda_{f d}}{L_{f d}}+\frac{\lambda_{1 d}}{L_{1 d}}\right)\right)-\omega L_{d q}^{\prime \prime} i_{q}
\end{aligned}
$$

Active power is expressed as

$$
p=v_{d} i_{d}+v_{q} i_{q}
$$

\section{B. State space representation of single machine infinite bus system}

The deviation in the speed and rotor angle with the change in field flux linkage under saturation condition with damper bar effect and considering the cross coupling between $d-q$ axis field. The state space matrix is [3].

$$
\dot{x}=A x+B u
$$

These equations get modified by considering the cross magnetizing phenomenon is:

In the above equations $\lambda_{a d}$ and $\lambda_{a q}$ are the air- gap flux linkages under saturation condition.

The air gap torque is

$$
\begin{aligned}
T_{e} & =\lambda_{d} i_{q}-\lambda_{q} i_{d} \\
& =\lambda_{a d} i_{q}-\lambda_{a q} i_{d}
\end{aligned}
$$

With $\frac{d}{d t} \lambda_{d}$ and $\frac{d}{d t} \lambda_{q}$ term i.e. (transient term) neglected.

\section{Network equation}

The machine, as network equations, can be expressed in terms of one reference frame of the machine because there is only one machine. So the machine and infinite bus terminal voltage can be resolved in terms of $\mathrm{d}$ and $\mathrm{q}$ axis components are.

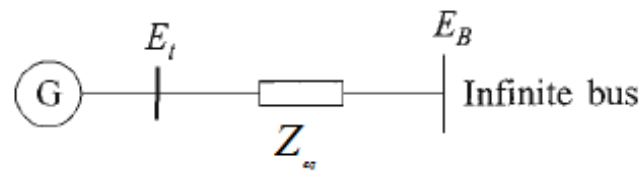

Figure 1. Machine connect to the infinity bus

The d-axis and q-axis voltage i.e. $V_{d}, V_{q}$ and the expression for $\lambda_{a d}, \lambda_{a q}$ then obtain $i_{d}$ and $i_{q}$ in terms of state variables $\lambda_{f d}$ and $\delta$ the rotor angle [3].

$$
\begin{aligned}
& i_{d}=\frac{X_{T q} E_{q N}-\left[\mathrm{R}_{T}+\mathrm{X}_{d q}\right] \mathrm{E}_{d N}}{D^{\prime}} \\
& i_{q}=\frac{\left[\mathrm{R}_{T}+\mathrm{X}_{q d}\right] \mathrm{E}_{q N}+X_{T d} E_{d N}}{D^{\prime}}
\end{aligned}
$$

where

$$
E_{b d}=E_{b} \sin \delta ; \quad \text { and } E_{b q}=E_{b} \cos \delta
$$

$$
\begin{aligned}
& X_{d q}=\omega L_{d q}^{\prime \prime}=\omega L_{d q} \frac{L_{a d}^{\prime \prime}}{L_{a d}} ; X_{q d}=\omega L_{q d}^{\prime \prime}=\omega L_{d q} \frac{L_{a q}^{\prime \prime}}{L_{a q}} ; \\
& \text { and } D^{\prime}=\left(R_{T}+X_{d q}\right)\left(R_{T}+X_{q d}\right)+X_{T q} X_{T d} \\
& X_{T d}=X_{E}+X_{d s}^{\prime \prime} ; X_{d s}^{\prime \prime}=\omega\left(L_{a d}^{\prime \prime}+L_{l}\right) ; R_{T}=R_{s}+R_{E} ; \\
& X_{T q}=X_{E}+X_{q s}^{\prime \prime} ; X_{q s}^{\prime \prime}=\omega\left(L_{a q}^{\prime \prime}+L_{l}\right) ;
\end{aligned}
$$

Here, $X_{T d}, X_{T q}$ is the total reactance, of machine with infinity bus in d-axis and q- axis respectively, $R_{s}$ is the armature resistance of machine and $R_{T}$ total resistant of system. 


$$
\begin{aligned}
& E_{b d}=E_{b} \sin \delta ; E_{b q}=E_{b} \cos \delta \\
& \mathrm{E}_{q N}=\mathrm{E}_{q}^{\prime \prime}-E_{b q}=\mathrm{E}_{q}^{\prime \prime}-\mathrm{E}_{b} \cos \delta ; \mathrm{E}_{q}^{\prime \prime}=\omega L_{a d}^{\prime \prime}\left(\frac{\lambda_{f d}}{L_{f d}}+\frac{\lambda_{1 d}}{L_{1 d}}\right) \\
& \mathrm{E}_{d N}=\mathrm{E}_{d}^{\prime \prime}+E_{b d}=\mathrm{E}_{d}^{\prime \prime}+\mathrm{E}_{b} \sin \delta ; \mathrm{E}_{d}^{\prime \prime}=\omega L_{a q}^{\prime \prime}\left(\frac{\lambda_{1 q}}{L_{1 q}}+\frac{\lambda_{2 q}}{L_{2 q}}\right)
\end{aligned}
$$

The reactance $X_{q s}^{\prime \prime}$ and $X_{d s}^{\prime \prime}$ are the saturated values in per unit. Now the equation (13) and (14) is written in linearization for state space model.

$$
\begin{aligned}
& \Delta i_{d}=m_{1}^{\prime} \Delta \delta+m_{2}^{\prime} \Delta \lambda_{f d}+m_{3}^{\prime} \Delta \lambda_{1 d}+m_{4}^{\prime} \Delta \lambda_{1 q}+m_{5}^{\prime} \Delta \lambda_{2 q} \\
& \Delta i_{q}=n_{1}^{\prime} \Delta \delta+n_{2}^{\prime} \Delta \lambda_{f d}+n_{3}^{\prime} \Delta \lambda_{1 d}+n_{4}^{\prime} \Delta \lambda_{1 q}+n_{5}^{\prime} \Delta \lambda_{2 q}
\end{aligned}
$$

The expression for $\Delta \lambda_{a d}$ and $\Delta \lambda_{a q}$ are given by

$$
\Delta \lambda_{\text {adequ }}=L_{a d}^{\prime \prime}\left(-\Delta i_{d}+\frac{\Delta \lambda_{f d}}{L_{f d}}+\frac{\Delta \lambda_{1 d}}{L_{1 d}}\right)-L_{d q}^{\prime \prime} \Delta i_{q}
$$

Substituting from the above equations

$$
\begin{gathered}
\Delta \lambda_{\text {adequ }}=\left(m_{1}^{\prime} L_{a d}^{\prime \prime}-n_{1}^{\prime} L_{d q}^{\prime \prime}\right) \Delta \delta+\left(L_{a d}^{\prime \prime}\left(\frac{1}{L_{f d}}-m_{2}^{\prime}\right)-n_{2}^{\prime} L_{d q}^{\prime \prime}\right) \Delta \lambda_{f d} \\
+\left(L_{a d}^{\prime \prime}\left(\frac{1}{L_{1 d}}-m_{3}^{\prime}\right)-n_{3}^{\prime} L_{d q}^{\prime \prime}\right) \Delta \lambda_{1 d}+\left(-m_{4}^{\prime} L_{a d}^{\prime \prime}-n_{4}^{\prime} L_{d q}^{\prime \prime}\right) \Delta \lambda_{1 q} \\
+\left(-m_{5}^{\prime} L_{a d}^{\prime \prime}-n_{5}^{\prime} L_{d q}^{\prime \prime}\right) \Delta \lambda_{2 q} \\
\Delta \lambda_{\text {aqequ }}=L_{a q}^{\prime \prime}\left(-\Delta i_{q}+\frac{\Delta \lambda_{1 q}}{L_{1 q}}+\frac{\Delta \lambda_{2 q}}{L_{2 q}}\right)-L_{q d}^{\prime \prime} \Delta i_{d}
\end{gathered}
$$

From the above equation

$$
\begin{aligned}
& \Delta \lambda_{\text {aqequ }}=\left(-n_{1}^{\prime} L_{a q}^{\prime \prime}-m_{1}^{\prime} L_{d q}^{\prime \prime}\right) \Delta \delta+\left(-n_{2}^{\prime} L_{a q}^{\prime \prime}-m_{2}^{\prime} L_{d q}^{\prime \prime}\right) \Delta \lambda_{f d} \\
& +\left(-n_{3}^{\prime} L_{a q}^{\prime \prime}-m_{3}^{\prime} L_{d q}^{\prime \prime}\right) \Delta \lambda_{1 d}+\left(L_{a q}^{\prime \prime}\left(\frac{1}{L_{1 q}}-n_{4}^{\prime}\right)-m_{4}^{\prime} L_{d q}^{\prime \prime}\right) \Delta \lambda_{1 q}(21) \\
& +\left(L_{a q}^{\prime \prime}\left(\frac{1}{L_{2 q}}-n_{5}^{\prime}\right)-m_{5}^{\prime} L_{d q}^{\prime \prime}\right) \Delta \lambda_{2 q}
\end{aligned}
$$

The expression for the electromagnetic torque developed by air gap by equation (12) is further solving for linearization as;

$$
\Delta T_{e}=\lambda_{a d 0} \Delta i_{q}+i_{q 0} \Delta \lambda_{a d}-\lambda_{a q 0} \Delta i_{d}-i_{d 0} \Delta \lambda_{a q}
$$

Substituting the value from equation (3), (18), (19),(20) and (21) in the equation (22)

$$
\Delta T_{e}=\mathrm{k}_{1}^{\prime} \Delta \delta+\mathrm{k}_{2}^{\prime} \Delta \lambda_{f d}+\mathrm{k}_{21}^{\prime} \Delta \lambda_{1 d}+\mathrm{k}_{22}^{\prime} \Delta \lambda_{1 q}+\mathrm{k}_{23}^{\prime} \Delta \lambda_{2 q}
$$

From the speed-motion equation

$$
\frac{d}{d t} \Delta \omega_{r}=\frac{1}{2 H}\left[\Delta T_{M}-\Delta T_{e}-\Delta K_{D} \Delta \omega_{r}\right]
$$

The value of $\Delta T_{e}$ from equation (23) is putting in the above equation

$$
\begin{aligned}
\frac{d \Delta \omega_{r}}{d t}= & \mathrm{a}_{11} \Delta \omega_{r}+\mathrm{a}_{12} \Delta \delta+\mathrm{a}_{13} \Delta \lambda_{f d}+\mathrm{a}_{14} \Delta \lambda_{1 d} \\
& +\mathrm{a}_{15} \Delta \lambda_{1 q}+\mathrm{a}_{16} \Delta \lambda_{2 q}
\end{aligned}
$$

Similarly do for all state space equation [3]

$$
\begin{aligned}
& \frac{d \Delta \lambda_{f d}}{d t}=\frac{\omega_{0} R_{f d}}{L_{f d}} \Delta E_{f d}-\omega_{0} R_{f d} \frac{1}{L_{f d}}\left(\Delta \lambda_{f d}-\Delta \lambda_{a d}\right) \\
& \frac{d \Delta \lambda_{f d}}{d t}=\mathrm{a}_{31} \Delta \omega_{r}+\mathrm{a}_{32} \Delta \delta+\mathrm{a}_{33} \Delta \lambda_{f d}+\mathrm{a}_{34} \Delta \lambda_{1 d} \\
&+\mathrm{a}_{35} \Delta \lambda_{1 q}+\mathrm{a}_{36} \Delta \lambda_{2 q}
\end{aligned}
$$

The state matrix is:

$$
\dot{x}=A x+B u
$$

\section{Equation Expressed by Equivalent Synchronous} Reactance

Equivalent synchronous reactances are transformed equation into the form of equation (1), (2) so that it expressed at the time of saturation considering cross-magnetizing phenomenon.

$$
\begin{gathered}
\lambda_{d e q}=-\left[L_{d e q}\left(i_{d}-i_{f}\right)+L_{l s} i_{f}\right] \\
L_{d e q}=L_{a d e q}+L_{l s}=\left[L_{a d}+\frac{L_{d q}}{\left(i_{d}-i_{f}\right)} i_{q}\right]+L_{l s} \\
\lambda_{\text {adeq }}=\left[L_{a d}+\frac{L_{d q}}{\left(i_{d}-i_{f}\right)} i_{q}\right]\left(i_{d}-i_{f}\right) \\
\lambda_{\text {adequ }}=L_{a d}^{\prime \prime}\left(-i_{d}+\frac{\lambda_{f d}}{L_{f d}}+\frac{\lambda_{1 d}}{L_{1 d}}\right)-L_{d q}^{\prime \prime} i_{q} \\
\lambda_{\text {adequ }}=\lambda_{a d}-L_{d q}^{\prime \prime} i_{q} \\
\Delta \lambda_{\text {adequ }}=L_{a d}^{\prime \prime}\left(-\Delta i_{d}+\frac{\Delta \lambda_{f d}}{L_{f d}}+\frac{\Delta \lambda_{1 d}}{L_{1 d}}\right)-L_{d q}^{\prime \prime} \Delta i_{q} \\
\lambda_{q}=-L_{q e q} i_{q}
\end{gathered}
$$

Where $L_{d e q}$ is

$$
\begin{gathered}
L_{q e q}=L_{a q e q}+L_{l s}=\left[L_{a q}+L_{d q} \frac{i_{d}}{i_{q}}-L_{f q} \frac{i_{f}}{i_{q}}\right]+L_{l s} \\
\lambda_{a q e q}=\left[L_{a q}+L_{d q} \frac{i_{d}}{i_{q}}-L_{f q} \frac{i_{f}}{i_{q}}\right] i_{q} \\
L_{q e q}=L_{a q e q}+L_{l s} \\
L_{a q e q}=L_{a q}+L_{d q} \frac{i_{d}}{i_{q}}-L_{f q} \frac{i_{f}}{i_{q}} \\
\Delta \lambda_{a q e q u}=L_{a q}^{\prime \prime}\left(-\Delta i_{q}+\frac{\Delta \lambda_{1 q}}{L_{1 q}}+\frac{\Delta \lambda_{2 q}}{L_{2 q}}\right)-L_{q d}^{\prime \prime} \Delta i_{d}
\end{gathered}
$$




\section{RESULTS AND DISCUSSIONS}

The effect of field flux variation (i.e. armature reaction) adds a damping torque component and thus to reduce synchronizing torque slightly.

With saturation effect: The change in air gap torque is from the eigenvalues at complex frequencies we get computing the value of synchronizing torque and Damping torque component. The system instability due to lack of synchronizing torque. This is reflected in the real eigenvalue becoming slightly positive which representing a mode of instability through a non-oscillatory mode.

Without saturation effect: The system is on the verge of instability. Rotor angle is approximate to $90 \mathrm{deg}$. With constant voltage if the value of and is used to compute initial operating condition are the same as the values used to relate incremental flux linkage and Current. The effect of amortisseurs with cross coupling is to increase the damping ratio from 0.0265 to 0.0491 and reduced the frequency very slightly.

\section{A. Speed deviation}

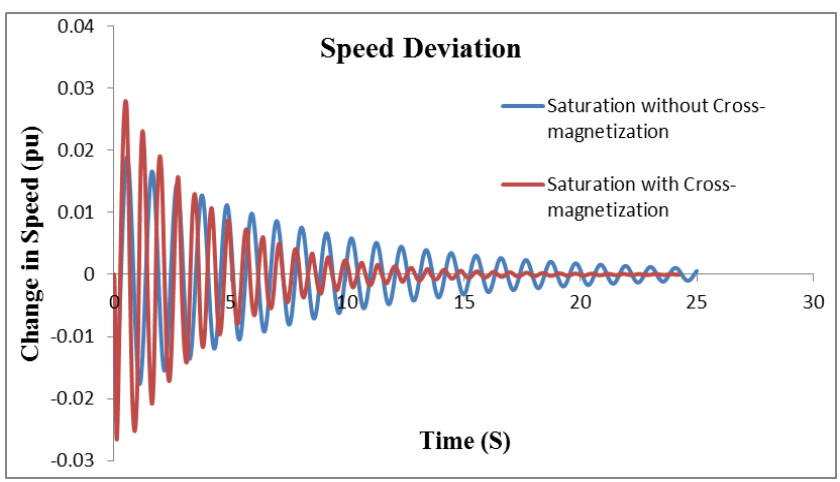

Fig. 1. Speed deviation as a function of time. Under the saturation considering cross-magnetization effect and without cross- magnetization effect.

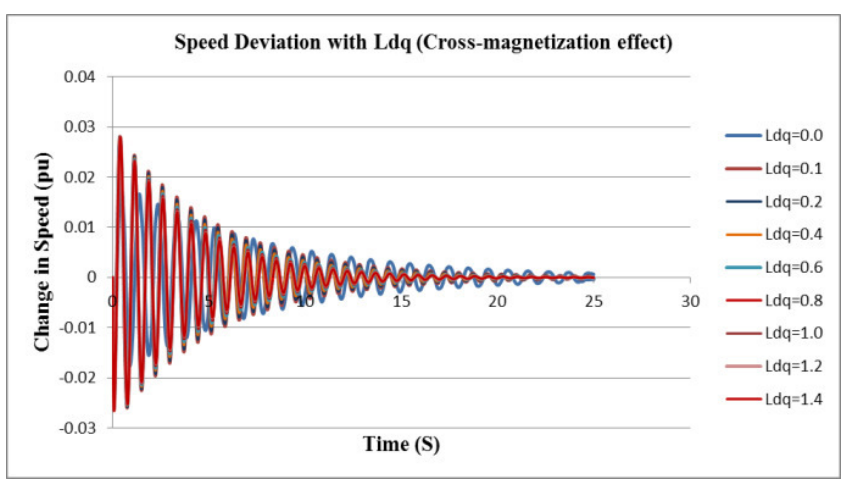

Fig. 2. Speed deviation as a function of time. Under the saturation considering cross-magnetization effect at various cross-coupling inductances.

\section{B. Rotor angle deviation}

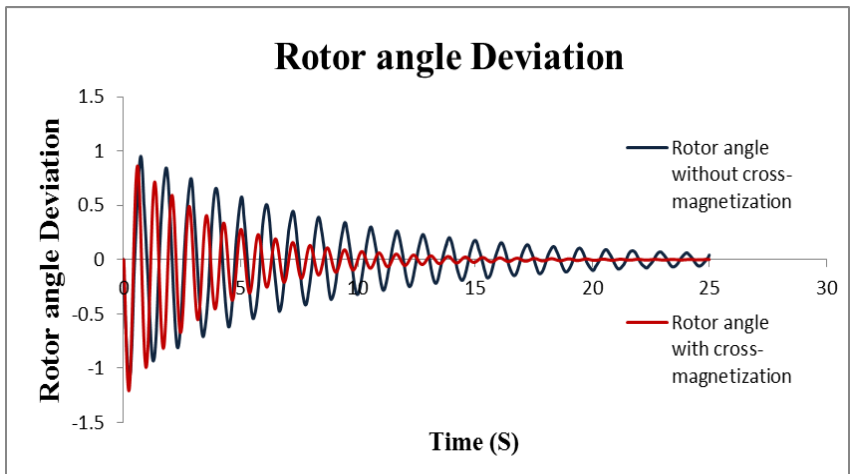

Fig. 3. Rotor angle deviation in pu as a function of time. Under the saturation without cross-magnetization and with cross- magnetization effect.

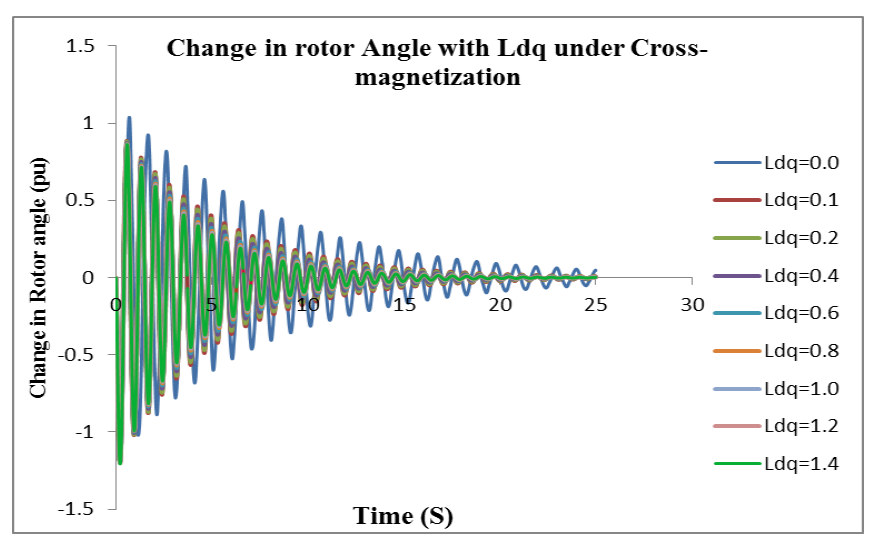

Fig. 4. Rotor angle deviation as a function of time. Under the saturation considering cross-magnetization effect at various cross-coupling inductances.

TABLE I

PARAMETERS OF PROPOSED MODEL WITH SATURATION AND WITHOUT SATURATION

\begin{tabular}{|c|c|c|c|c|c|c|}
\hline Model & $\begin{array}{l}\mathbf{P}( \\
\pm 0.25 \mathbf{p u} \\
) \\
\text { Limit }\end{array}$ & $\mathbf{Q}$ & $E_{b}$ & $\begin{array}{l}\delta \\
(\mathrm{deg})\end{array}$ & $E_{f}$ & $\begin{array}{l}\text { Eigen- } \\
\text { values }\end{array}$ \\
\hline $\begin{array}{l}\text { Propos } \\
\text {-ed } \\
\text { Model } \\
\text { with } \\
\text { Satura- } \\
\text { tion }\end{array}$ & 1.3847 & 0.4625 & $\begin{array}{l}1.14 \\
13\end{array}$ & $\begin{array}{l}79.11 \\
26\end{array}$ & 3.3 & $\begin{array}{l}-0.29321 \\
\pm j 5.9632 \\
0.00142 \\
.\end{array}$ \\
\hline $\begin{array}{l}\text { Propos } \\
\text { ed } \\
\text { Model } \\
\text { without } \\
\text { Satura- } \\
\text { tion } \\
\end{array}$ & 1.0137 & 0.3458 & $\begin{array}{l}1.02 \\
75\end{array}$ & 89.60 & $\begin{array}{l}2.4 \\
9\end{array}$ & $\begin{array}{l}-0.162 \\
\pm j 6.08 \\
- \\
0.00006\end{array}$ \\
\hline
\end{tabular}


TABLE II

SUMMARY OF FREQUNCY OF ROT OR OSCILLATION, DAMPING RATIO, $K_{S}$ AND $K_{D}$, WITH DIFFERENT T YPE OF MODEL BASED ON RESULTS

\begin{tabular}{|l|l|l|l|}
\hline Model & $\begin{array}{l}\text { Classical } \\
\text { Model }\end{array}$ & $\begin{array}{l}\text { Constant } \\
E_{f d}\end{array}$ & $\begin{array}{l}\text { Proposed Model } \\
\text { with } \begin{array}{c}\text { cross- } \\
\text { magnetization }\end{array}\end{array}$ \\
\hline $\begin{array}{l}\lambda_{1}, \lambda_{2} \\
\text { eigenvalues }\end{array}$ & $j 6.41$ & $-0.11 \pm j 6.41$ & $-0.29321 \pm j 5.9632$ \\
\hline$\omega_{d}$ & $1.02 \mathrm{~Hz}$ & $1.07 \mathrm{~Hz} \quad$ & $0.94907 \mathrm{~Hz}$ \\
\hline$\omega_{n}$ & - & $\begin{array}{l}6.47 \\
1.03 \mathrm{~Hz}\end{array}$ & $\begin{array}{l}5.9704 \mathrm{rad} / \mathrm{s} \quad 0.96 \\
\mathrm{~Hz}\end{array}$ \\
\hline$\xi$ & 0 & 0.017 & 0.049111 \\
\hline$K_{g}$ & 0.757 & 0.763 & 0.80719 \\
\hline$K_{d}$ & 0 & 1.53 & 0.21522 \\
\hline
\end{tabular}

\section{Discussion}

By considering cross-magnetization effect under saturation condition, the change in speed, rotor angle deviation and change in field flux linkage of a synchronous machine, due to this magnitude is increased slightly. And the time of oscillation is reduced.

Change in the flux linkage of $d$-axis damper bar remains same in both cases i.e. saturation and saturation with crossmagnetization effect.

\section{CONCLUSION}

The work presents an integrated perspective on synchronous machine modeling, considering the cross-magnetization effect under the saturation condition that gives the actual representation of machine. The model retains the computational efficiency of the single machine to infinite bus system under saturation and $d q$-axis theoretical framework.

This model gives the state space representation. And suitable for small and large signal time domain simulation for the power system.

\section{APPENDIX-I}

Table-IV

Synchronous machine Parameters used for Simulation

\begin{tabular}{|l|l|l|l|}
\hline Sr. No & Symbol & Parameters Name & Value $(\mathrm{pu})$ \\
\hline 1 & $R_{s}$ & Armature Resistance & 0.003 \\
\hline 2 & $R_{f d}$ & Field winding Resistance & 0.0006 \\
\hline 3 & $R_{1 d}$ & $\begin{array}{l}\text { d-axis Damper winding } \\
\text { Resistance }\end{array}$ & 0.0284 \\
\hline 4 & $R_{1 q}$ & $\begin{array}{l}\text { q-axis Damper winding 1 } \\
\text { Resistance }\end{array}$ & 0.00619 \\
\hline 5 & $R_{2 q}$ & $\begin{array}{l}\text { q-axis Damper winding 2 } \\
\text { Resistance }\end{array}$ & 0.02368 \\
\hline 6 & $L_{a d}$ & d-axis Magnetizing Inductance & 1.66 \\
\hline 7 & $L_{a q}$ & q-axis Magnetizing Inductance & 1.61 \\
\hline 8 & $L_{l s}$ & Leakage Inductance & 0.15 \\
\hline
\end{tabular}

\begin{tabular}{|l|l|l|l|}
\hline 9 & $L_{f d}$ & Field Inductance & 0.165 \\
\hline 10 & $L_{1 d}$ & d-axis damper bar Inductance & 0.1713 \\
\hline 11 & $L_{1 q}$ & $\begin{array}{l}\text { q-axis damper bar 1 } \\
\text { Inductance }\end{array}$ & 0.7252 \\
\hline 12 & $L_{2 q}$ & $\begin{array}{l}\text { q-axis damper bar 2 } \\
\text { Inductance }\end{array}$ & 0.125 \\
\hline
\end{tabular}

\section{REFERENCES}

[1] K. Ide, K. Shima, M. Takahashi, "Analysis of Saturated Synchronous Reactances of Large Turbine Generat or by Considering Cross-Magnetizing Reactances Using Finite Elements" IEEE Transactions on Energy Conversion, Vol. 14, pp.66-71, March 1999.

[2] E. F. Fuchs and E. A. Erdelyi, "Determination of Waterwheel Altemator Steady- State Reactanas fmm Flux Plots", IEEET rans. On Power Apparatus and Systems, Vol. PAS-91, 1972, pp. 25102527.

[3] P.kundur, "Power system stability and control".

[4] D. C. Aliprantis, S. D. Sudhoff, and B. T. Kuhn, "A synchronous machine model with saturation and arbitrary rotor network representation," IEEE Trans. Energy Convers., vol. 20, no. 3, pp. 584-594, Sep. 2005.

[5] S. H. Minnich, R. P. Schulz, D. H. Baker, D. K. Sharma, R. G. Farmer and J. H. Fish, "Saturation Functions for Synchronous Generators from Finite Element", IEEE Trans. on Energy Conversion, Vol. 2, 1987, pp 680-692.

[6] F.P. deMello and C.Corcordia, "Concept of Synchronous Machine Stability as Affected by Excitation Control," IEEE Trans., Vol. PAS-88, pp. 316-329, April 1969..

[7] A. M. El-Senfi, A. S. Abdallah, M. K. El-Shetbiny and E. H. Badawy, "Experimental Study of the Saturation and Cross-Magneti zing Phenomenon in Saturated Synchronous Machines", IEEE Trans. on Energy Conversion, Vol. 3, 1988, pp.

[8] A. M. El-Senfi and A. S. Abdallah, "Saturated Synchronous Reactances of Synchronous Machines", IEEE Trans. on Energy Conversion, Vol. 7, No. 3, 1992, pp. 570-579.

[9] S. R. Chaudhry, S. Ahmed- Zaid and N. A. Demerdash, "Coupled Finite-Element / State-Space Modeling of Turbogenentors in the ABC Frame of Reference - The Short-Ci m i t and Load Cases Including Saturated Parameters", IEEE Trans. On Energy Conversion, Vol. 10, 815-823.

[10] E. F. Fuchs and E. A. Erdelyi, "Determination of Waterwheel Altemator Steady- State Reactanas fmm Flux Plots", IEEETrans. On Power Apparatus and Systems, Vol. PAS-91, 1972, pp. 25102527.

[11] N. A. Demerdash and H. B. Hamilton, "A Simplified Approach to Determination of Saturated Synchronous Reactances of Large Turbogenentors Under Load", IEEE Trans. on Power Apparatus and Systems, Vol. PAS-95, No. 2, 1976, pp. 560-569.

[12] A. M. El-Senfi and A. S.Abdallah, "Saturated Synchronous Reactances of Synchronous Machines", IEEE Trans. on Energy Conversion, Vol. 7, No. 3, 1992, pp. 570-579.

[13] S. R. Chaudhry, S. Ahmed-Zaid and N. A. Demerdash,"Coupled Finite-Element / State-Space Modeling of Turbogenentors in the ABC Frame of Reference - The Short-Ci m i t and Load Cases Including Saturated Parameters", IEEE Trans. On Energy Conversion, Vol. 10, NO. 1, 1995, pp. 63-70. 